\title{
IDENTIFIKASI FEMALE ATHLETE TRIAD (FAT) PADA ATLET PERSATUAN ANGKAT BESI, BERAT, DAN BINARAGA SELURUH INDONESIA (PABBSI) DIY
}

\section{Oleh:}

\section{Cerika Rismayanthi dan Kukuh Wahyudin Pratama* Dosen Jurusan Pendidikan Kesehatan dan Rekreasi FIK UNY}

\begin{abstract}
Abstrak
Penelitian ini bertujuan untuk mengetahui identifikasi female athlete triad (FAT) pada atlet PABBSI putri Daerah Istimewa Yogyakarta. Penelitian ini merupakan penelitian deskriptif menggunakan metode survei dengan teknik pengambilan datanya menggunakan angket. Subyek dalam penelitian ini adalah atlet putri PABBSI DIY yang berjumlah 26 atlet. Teknik analisis data menggunakan analisis deskriptif yang dituangkan dalam bentuk persentase identifikasi FAT pada atlet PABBSI putri Daerah Istimewa Yogyakarta, yang terbagi dalam lima kategori.

Hasil penelitian menunjukkan bahwa identifikasi FAT pada atlet PABBSI putri Daerah Istimewa Yogyakarta adalah sedang. Secara rinci berdasarkan kecenderungan FAT, yaitu sebanyak 3atlet (11,54 \%) masuk dalam kategori sangat tinggi, 3 atlet $(11,54 \%)$ masuk dalam kategori tinggi, 13 atlet $(50,00 \%)$ masuk dalam kategori sedang, 5 atlet $(19,23 \%)$ masuk dalam kategori rendah, dan 1 atlet $(3,85 \%)$ masuk dalam kategori sangat rendah. Berdasarkan faktor risiko FAT, yaitu sebanyak sebanyak 4 atlet $(15,38 \%)$ yang masuk dalam kategori sangat tinggi, 5 atlet $(19,23 \%)$ masuk dalam kategori tinggi, 12 atlet $(46,15 \%)$ masuk dalam kategori sedang, 2 atlet $(7,69 \%)$ masuk dalam kategori rendah, dan 3 atlet $(11,54 \%)$ masuk dalam kategori sangat rendah.
\end{abstract}

Kata Kunci: female athlete triad (FAT), atlet PABBSI Putri

Angkat besi dan angkat berat adalah cabang olahraga yang bersaing untuk mengangkat beban berat yang disebut dengan barbel. Binaraga adalah kegiatan pembentukan tubuh yang melibatkan hipertrofi otot intensif dengan melakukan latihan beban dan diet protein tinggi

Identifikasi Female Athlete Triad (FAT) pada Atlet Persatuan Angkat Besi, Berat, dan Binaraga Seluruh Indonesia (PABBSI) DIY (Kukuh Wahyudin Pratama dan Cerika Rismayanthi) 


\section{Ket *: Mahasiswa Prodi Ilmu Keolahragaan (Ikor) FIK UNY}

secara rutin dan intensif. Pola latihan yang dijalankan atlet angkat besi putri dan atlet angkat berat putri DIY tidak jauh berbeda dengan pola latihan yang dijalankan atlet putra. Atlet putri tetap melakukan latihan dengan intensitas tinggi untuk mencapai tujuan latihan yaitu meningkatkan kekuatan dan massa otot. Saat mendekati kompetisi, atlet dapat melakukan 2 sesi latihan dalam satu hari. Pagi hari melakukan latihan cardio yang dilanjutkan dengan program weight training berintensitas 80-95\% untuk menambah kekuatan otot, sore harinya melakukan program latihan body building untuk menyempurnakan teknik dan menambah massa otot. Selain itu tidak jarang pula atlet putri yang memerlukan rangsangan hormon layaknya pria yaitu mengonsumsi anabolik steroid yang bertujuan untuk untuk meningkatkan kekuatan dan membentuk massa otot.

Atmosfir persaingan atlet angkat besi putri dan atlet angkat berat putri DIY semakin meningkat oleh sebab itu tidak dapat dipungkiri apabila kondisi psikologis atlet terkadang tidak mementu. Hal ini menyebabkan pengaruh pada pola latihan, istirahat, dan pola makan. Kebutuhan akan gizi atlet putri harus mendapatkan perhatian yang lebih karena di sini atlet angkat besi putri dan atlet angkat berat putri DIY akan sangat menjaga berat badannya agar tetap pada kelas yang dipertandingkan dan diusahakan tidak mengalami peningkatan berat badan melebihi kelasnya. Walaupun demikian, semakin disadari bahwa kegiatan fisik dengan intensitas tinggi juga dapat mengakibatkan dampak negatif bagi kesehatan mental, sosial maupun fisiologis atlet (Torstveit, 2005: 91). Banyak keluhan yang dialami oleh atlet angkat besi putri di antaranya adalah female athlete triad (FAT).

FAT merupakan suatu sindrom yang sering terjadi pada atlet wanita dengan aktivitas fisik intensitas tinggi (Toerstveit, 2005: 91). FAT merupakan kombinasi dari tiga gejala yang berkaitan satu sama lain yang diasosiasikan dengan latihan fisik intensitas tinggi yang dilakukan oleh atlet (Nattiv et al, 1994: 23). Tiga gejala tersebut meliputi: (1) anorexia nervosa, (2) amenorea, dan (3) osteoporosis (Nattiv et al, 1994: 23). Dua penyebab utama FAT yang mendasari keseluruhan gejala tersebut adalah 1) intensitas latihan fisik yang terlalu tinggi yang tidak mampu dikompensasi fisiologis tubuh dan 2) tekanan mental yang berat akibat kompetisi olahraga yang mencetuskan gangguan perilaku makan (Nattiv et al,1994: 18). Pada mulanya, gejala FAT bersifat ringan dan hingga sampai saat ini belum 
diketahui persentase klasifikasi yang dialami oleh atlet angkat besi putri dan atlet angkat berat putri DIY. Penemuan kelelahan kronis, anemia, ketidakseimbangan elektrolit, dan depresi pada pemeriksaan fisik merupakan petunjuk awal kemungkinan gejala FAT. Amenorea yang terjadi akibat latihan fisik dengan intensitas tinggi bukan merupakan diagnosis klinis dan tidak bisa dibuktikan pada pemeriksaan laboratorium. Pemeriksaan fisik dan wawancara mendalam perlu dilakukan pada atlet wanita yang mengalami amenorea untuk menentukan kemungkinan penyebab dari amenorea yang lain (Kaziz, 2003: 17). Hal ini bertentangan dengan tujuan olahraga yang di antaranya menjadikan tubuh sehat dan bugar, akan tetapi justru menimbulkan penyakit akibat olahraga itu sendiri. Hal ini menjadi tanggung jawab bagi pelatih, dokter olahraga, orang tua, dan pengelola kompetisi olahraga untuk meminimalkan, mencegah, mengobati, dan menangani resiko terjadinya FAT.

\section{Definisi Female Athlete Triad (FAT)}

Toerstveit (2005: 95) menggambarkan kondisi yang progresif pada FAT di antaranya:

1. Gangguan pola makan pada atlet yang melakukan latihan olahraga tingkat tinggi akan menyebabkan gangguan menstruasi.

2. Wanita tidak menstruasi karena gangguan/kekurangan produksi hormon estrogen, sedangkan hormone estrogen ini penting untuk pembentukan tulang. Apabila hal ini disertai gangguan pola makan, akan terjadi kekurangan asupan $\mathrm{Ca}^{2+}$ dan protein, yang menyebabkan tulang menjadi tipis dan terjadi osteoporosis yang teratur.

3. Tulang yang lemah mudah mengalami stress fracture, khususnya oleh aktivitas fisik yang tinggi pada atlet wanita.

Atlet wanita harus dikonsultasikan ke dokter apabila:

1. Terdapat tanda-tanda gangguan pola makan.

2. Belum mendapat menstruasi ketika umur telah mencapai 16 tahun.

3. Terdapat stress fracture. 
Mekanisme proses fisiologis terjadinya FAT, tersaji pada Gambar 1 berikut ini:

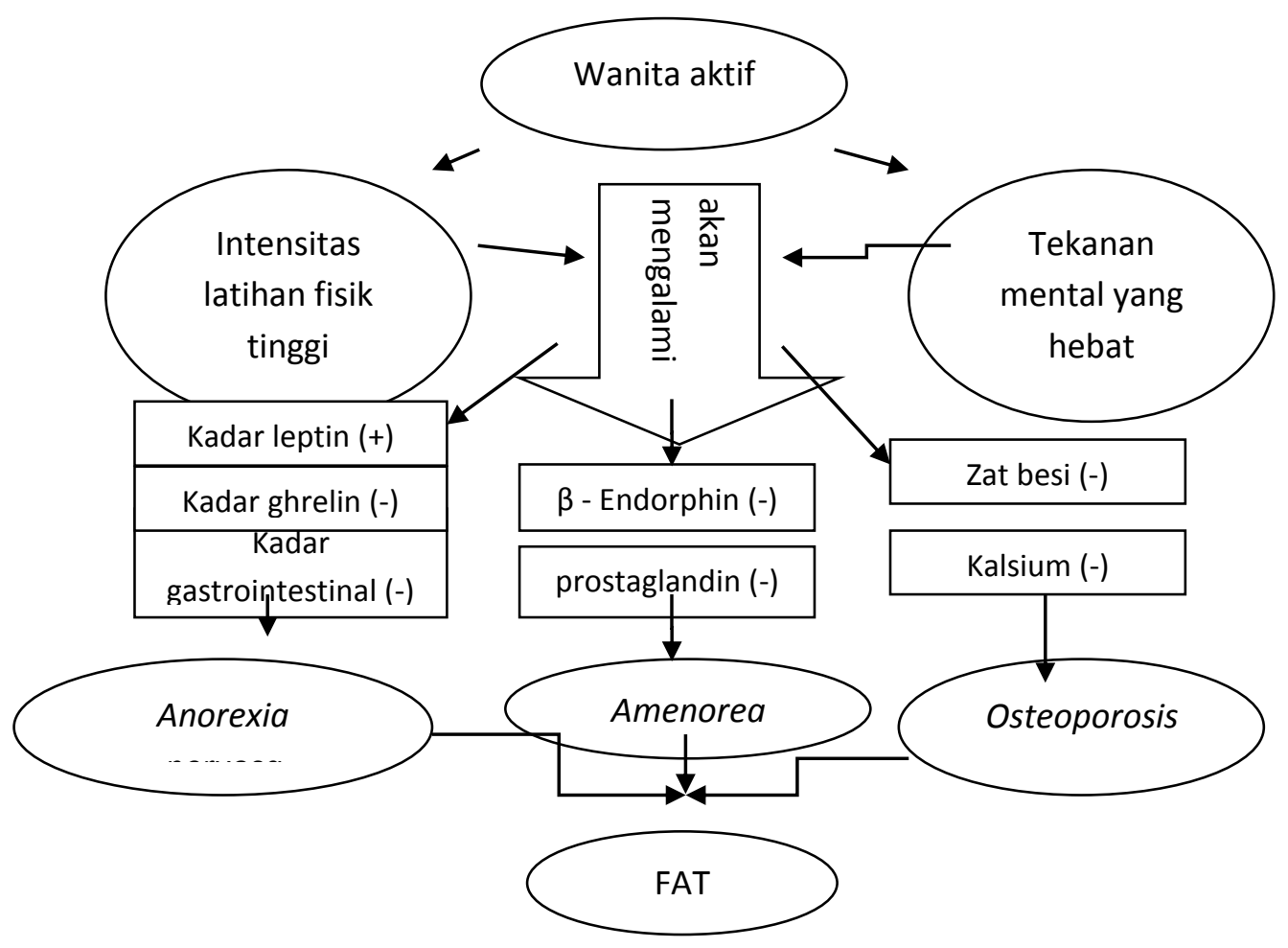

Gambar 1. Proses Fisiologis Terjadinya FAT

FAT adalah suatu sindrom yang sering terjadi pada atlet wanita dengan aktivitas fisik intensitas tinggi (Toerstveit,2005: 91). FAT merupakan kombinasi dari tiga gejala yang berkaitan satu sama lain yang diasosiasikan dengan latihan fisik intensitas tinggi yang dilakukan oleh atlet (Nattiv et al, 1994: 23). Tiga gejala tersebut meliputi: (a) anorexia nervosa, (b) amenorea, dan (c) osteoporosis (Nattiv et al, 1994: 23). Meskipun FAT diasosiasikan dengan olahraga, FAT tidak hanya terjadi pada atlet. Selain atlet, salah satu populasi lain yang berisiko mengalami FAT adalah wanita yang aktif dalam kegiatan fisik dalam dunia militer (Lauder et al, 1998: 64). 


\section{A. Gejala FAT}

\section{Anorexia Nervosa}

Anorexia nervosa adalah perilaku seseorang yang berhubungan dengan: (a) menolak mempertahankan berat badan minimal, (b) sangat takut terhadap kegemukan meskipun berat badannya sangat kurang, dan (c) mengeluh merasa gemuk meskipun sebenarnya sudah sangat kurus atau merasa bahwa suatu bagian tubuhnya terlihat gemuk. Anorexia nervosa merupakan masalah yang cukup banyak dijumpai pada atlet wanita, terutama pada mereka yang berpartisipasi dalam kegiatan-kegiatan olahraga yang memerlukan kecantikan dan kekuatan seperti senam, tari, dayung, dan angkat besi. Anorexia nervosa sering juga terjadi pada wanita muda yang tujuan berolahraga dengan tujuan utama menata (menurunkan) berat badan.

Indikasi awal seseorang memiliki risiko anorexia nervosa adalah ketika asupan makanan yang dimakan tidak sesuai dengan kebutuhan asupan sehari-hari. Tandatanda anorexia nervosa menurut Toerstveit (2005: 108) adalah: (a) menggolonggolongkan makanan yang baik dan makanan yang dianggap jelek bagi tubuhnya, (b) menghindari pertemuan yang menyediakan makanan, (c) pikiran selalu tertuju pada masalah makan, kalori, dan berat badan, (d) berat badan menurun drastis, (e) berlatih keras dan tidak mengenal lelah, (f) tiba-tiba berniat tidak makan daging warna merah, (g) takut gemuk, (h) tidak datang bulan (wanita), (i) rambut rontok, (j) denyut nadi lambat dan lemah, (k) sensitif pada suhu dingin, (l) gugup saat makan, (m) mudah menangis, dan (n) memotong makanan menjadi kecil-kecil dan memainmainkannya.

\section{Amenorea}

Istilah amenorea atlet dimaksudkan untuk mendeskripsikan berhentinya menstruasi yang dialami beberapa atlet selama masa latihan dan kompetisi berat. Perubahan menstruasi dapat berupa berkurangnya jumlah menstruasi pertahun oligomenorea; atau sama sekali tidak ada menstruasi - amenorea. Amenorea dapat dibedakan menjadi dua jenis yakni amenorea primer dan amenorea sekunder. Pada 
amenorea primer tidak terjadi fase menstruasi pada: (a) umur 14 tahun tanpa ada tanda-tanda perkembangan seks sekunder dan (b) umur 16 dengan pertumbuhan tanda seks sekunder. Amenorea sekunder didefinisikan sebagai ketiadaan menstruasi selama 6 bulan pada wanita yang biasanya memiliki siklus menstruasi yang normal atau 12 bulan pada wanita dengan siklus menstruasi yang panjang (oligomenorrea).

Amenorea dapat bersifat primer yaitu tertundanya menstruasi pertama (menarche) atau sekunder yaitu setelah menstruasi terjadi beberapa kali secara normal. Amenorea dengan aktivitas fisik, intensitas tinggi dan penurunan berat badan pada atlet wanita dan disebabkan oleh gangguan pada fungsi hipotalamus. Pada keadaan ini terjadi penurunan produksi estrogen (Kazis, 2003: 15).

Adanya perubahan menstruasi pada atlet wanita sulit diketahui, karena munculnya berbagai bentuk gangguan menstruasi, dari fase luteal yang pendek sampai kepada amenorea. Definisi amenorea yaitu apabila dalam kurun waktu 3 bulan berturut-turut tidak terjadi menstruasi, atau menstruasi terjadi tidak lebih dari 3 kali dalam setahun. Perubahan-perubahan yang mungkin terjadi dalam siklus reproduksi atlet wanita, dapat dilihat pada Gambar 2 sebagai berikut:
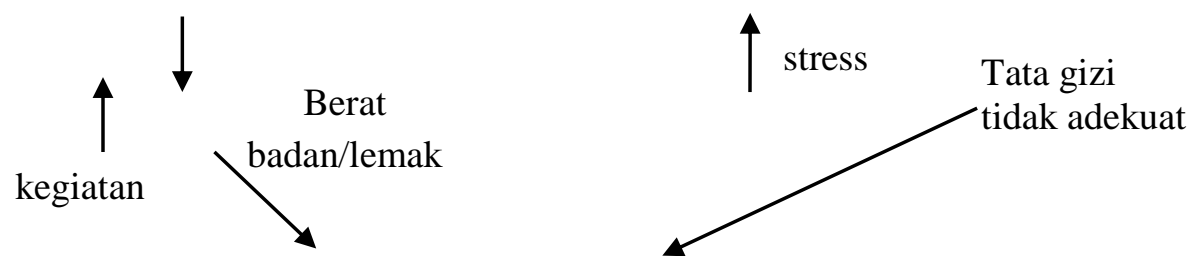

Disfungsi hypothalamus/pituitaria

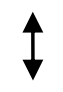

Disfungsi ovarium

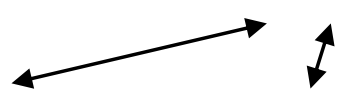

Fase luteal tidak adekuat $\leftrightarrow$ anovula

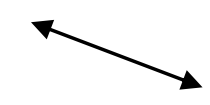

$\longleftrightarrow$ oligomenor $\longleftrightarrow$ amenorea

Gambar 2. Perubahan-Perubahan yang Terjadi dalam Siklus Reproduksi Atlet Wanita 
Gejala yang mungkin ditemukan pada amenore adalah sakit kepala, galaktore (pembentukan air susu pada wanita yang tidak hamil dan tidak sedang menyusui), gangguan penglihatan (pada tumor hipofisa), penurunan atau penambahan berat badan yang berarti, vagina yang kering, hirsutisme (pertumbuhan rambut yang berlebihan, yang mengikuti pola pria), perubahan suara, dan perubahan ukuran payudara.

\section{Osteoporosis}

Osteoporosis berasal dari kata osteo dan porous, osteo artinya tulang, dan porous berarti berlubang-lubang atau keropos. Jadi, osteoporosis adalah tulang yang keropos, yaitu penyakit yang mempunyai sifat khas berupa massa tulangnya rendah atau berkurang, disertai gangguan mikro-arsitektur tulang dan penurunan kualitas jaringan tulang, yang dapat menimbulkan kerapuhan tulang (Tandra, 2011: 24). Menurut WHO pada International Consensus Development Conference, di Roma, Itali, 1992 Osteoporosis diartikan sebagai penyakit dengan sifat-sifat khas berupa massa tulang yang rendah, disertai perubahan mikroarsitektur tulang, dan penurunan kualitas jaringan tulang, yang pada akhirnya menimbulkan akibat meningkatnya kerapuhan tulang dengan risiko terjadinya patah tulang (Suryati, 2006: 7).

\section{METODE PENELITIAN}

Penelitian ini adalah penelitian deskriptif yang menggunakan pendekatan kuantitatif. Metode penelitian ini menggunakan pendekatan sense-making dalam membingkai pertanyaan penelitian, teknik pengumpulan data, dan analisisnya.

Populasi dalam penelitian ini adalah atlet angkat besi putri dan atlet angkat berat putri DIY dengan jumlah 26 orang. Penelitian ini adalah penelitian populasi karena seluruh anggota populasi menjadi subjek penelitian. Kriteria inklusi penelitian di antaranya sebagai berikut: (1) atlet yang masih aktif ditingkat provinsi dan nasional, (2) dalam kondisi siap bertanding karena mendekati kompetisi, dan (3) melakukan latihan intensitas tinggi lebih dari 7 kali dalam seminggu. 
Teknik pengumpulan data yang digunakan dalam penelitian ini adalah dengan memberikan angket kepada responden tentang kejadian FAT untuk diisi tiap pertanyaan sesuai petunjuk yang ada dalam angket. Teknik analisis data dalam penelitian ini menggunakan teknik analisis data deskriptif kuantitatif. Adapun langkah-langkah yang digunakan yaitu: (1) menjumlahkan skor jawaban responden, (2) membuat persentase, dan (3) mengategorikan hasil persentase.

\section{HASIL PENELITIAN}

Hasil penelitian tentang identifikasi FAT secara objektif untuk identifikasi FAT yang dialami oleh atlet angkat besi dan atlet angkat berat putri DIY adalah tentang kendali anorexia nervosa, amenorea, dan osteoporosis. Di sisi lain secara subjektif untuk identifikasi FAT yang dialami oleh atlet angkat besi dan atlet angkat berat putri DIY adalah kecendrungan FAT dan faktor risiko FAT. Berikut ini data identifikasi FAT secara objektif dan subjektif.

\section{Secara Objektif}

a. Kendali Anorexia Nervosa

Kendali anorexia nervosa merupakan salah satu dari faktor objektif dalam identifikasi FAT yang dialami oleh atlet angkat besi putri dan atlet angkat berat putri DIY. Pada penelitian ini kendali anorexia nervosa dibagi menjadi dua kategori yaitu apabila lebih atau sama dengan dari kebutuhan kalori akan masuk dalam kategori tidak anorexia nervos, sedangkan jika kurang dari kebutuhan kalori maka akan masuk dalam kategori anorexia nervosa. Tabel 1 merupakan pengkategorian kendali anorexia nervosa pada identifikasi FAT yang dialami oleh atlet atlet angkat besi putri dan atlet angkat berat putri DIY. 
Tabel 1. Kategorisasi Identifikasi FAT yang Dialami oleh Atlet Angkat Besi Putri dan Atlet Angkat Berat Putri DIY secara Objektif pada Kendali Anorexia Nervosa

\begin{tabular}{|l|l|c|c|}
\hline \multicolumn{1}{|c|}{ Interval Kelas } & \multicolumn{1}{|c|}{ Kategori } & Frekuensi & Persentase \\
\hline$\geq$ Kebutuhan Kalori & Tidak Anorexia Nervosa & 0 & $0 \%$ \\
\hline < Kebutuhan Kalori & Anorexia Nervosa & 26 & $100 \%$ \\
\hline \multicolumn{2}{|r|}{ Jumlah } & 26 & $100 \%$ \\
\hline
\end{tabular}

Faktor utama yang menjadi penyebab atlet angkat besi putri dan atlet angkat berat putri DIY mengalami anorexia nervosa adalah peminimalisasian pola makan agar berat badan tidak melebihi kelas yang dipertandingkan.

b. Amenorea

Amenorea merupakan salah satu dari faktor objektif dalam identifikasi FAT yang dialami oleh atlet angkat besi putri dan atlet angkat berat putri DIY. Pada penelitian ini amenorea dibagi menjadi dua kategori yaitu amenorea sekunder dan amenorea primer. Tabel 2 merupakan pengategorian kendali amenorea pada identifikasi FAT yang dialami oleh atlet angkat besi putri dan atlet angkat berat putri DIY.

Tabel 2. Kategorisasi Identifikasi FAT yang Dialami oleh Atlet Angkat Besi Putri dan Atlet Angkat Berat Putri DIY secara Objektif pada Amenorea

\begin{tabular}{|c|l|c|c|}
\hline Interval Kelas & \multicolumn{1}{|c|}{ Kategori } & Frekuensi & Persentase \\
\hline$\leq 3$ bln tidak menstruasi & Amenorea Sekunder & 25 & $96,15 \%$ \\
\hline$\geq 4$ bln tidak menstruasi & Amenorea Primer & 1 & $3,85 \%$ \\
\hline \multicolumn{2}{|c|}{ Jumlah } & 26 & $100 \%$ \\
\hline
\end{tabular}

Faktor yang menjadi penyebab atlet angkat besi dan atlet angkat berat putri DIY mengalami amenorea adalah kondisi psikologis yang memengaruhi hypotalamus dalam sistem kerja pada siklus menstruasi atlet.

Identifikasi Female Athlete Triad (FAT) pada Atlet Persatuan Angkat Besi, Berat, dan Binaraga Seluruh Indonesia (PABBSI) DIY (Kukuh Wahyudin Pratama dan Cerika Rismayanthi) 
c. Kepadatan Tulang (Osteoporosis)

Kepadatan tulang merupakan salah satu dari faktor objektif dalam identifikasi FAT yang dialami oleh atlet angkat besi putri dan atlet angkat berat putri DIY. Tabel 3 merupakan pengategorian kendali osteoporosis pada identifikasi FAT yang dialami oleh atlet angkat besi dan atlet angkat berat putri DIY.

Tabel 3. Kategorisasi Identifikasi FAT yang Dialami oleh Atlet Angkat Besi dan Atlet Angkat Berat Putri DIY secara Objektif pada Kendali Osteoporosis

\begin{tabular}{|c|c|c|c|}
\hline Interval Kelas & Kategori & Frekuensi & Persentase \\
\hline$\leq-2,5$ & Tinggi & 0 & $0 \%$ \\
\hline$-2,5-(-1)$ & Sedang & 12 & $46,15 \%$ \\
\hline$>-1$ & Rendah & 14 & $53,85 \%$ \\
\hline \multicolumn{2}{|c|}{ Jumlah } & 26 & $100 \%$ \\
\hline
\end{tabular}

Faktor yang menjadi penyebab osteoporosis adalah ketika pola makan salah, asupan nutrisi yang diterima oleh tulang pun akan berkurang sementara pada hakikatnya ketika wanita mengalami menstruasi, zat-zat yang terbuang adalah termasuk kalsium dan zat besi.

\section{Secara Subjektif}

Secara subjektif pada identifikasi FAT yang dialami oleh atlet angkat besi putri dan atlet angkat berat putri DIYyaitu di bagi menjadi dua di antaranya adalah kecenderungan FAT dan faktor risiko FAT. Berikut adalah akan secara rinci dari kecenderungan FAT dan faktor risiko FAT.

a. Kecenderungan FAT

Berdasarkan FAT, diperoleh nilai maksimum $=11$; nilai minimum $=0$; rerata $=5$; standar deviasi $=2,64 ;$ median $=5$ dan modus $=6$. Selanjutnya, data dikategorikan menjadi lima kategori, yaitu kategori sangat rendah, rendah, sedang, tinggi, dan sangat tinggi berdasarkan nilai mean dan standar deviasi. Tabel 4 berikut 
merupakan distribusi frekuensi identifikasi FAT yang dialami atlet angkat besi putri dan atlet angkat berat putri DIY berdasarkan faktor FAT.

Tabel 4. Distribusi Frekuensi Identifikasi FAT yang Dialami Atlet Angkat Besi Putri dan Atlet Angkat Berat Putri DIY berdasarkan Faktor FAT

\begin{tabular}{|c|c|c|c|c|}
\hline$\overline{\text { No }}$ & Kelas Interval & Kategori & Frekuensi & Persentase \\
\hline 1 & $\geq 8,96$ & Sangat tinggi & 3 & $11,54 \%$ \\
\hline 2 & $6,32-8,95$ & Tinggi & 3 & $11,54 \%$ \\
\hline 3 & $3,68-6,31$ & Sedang & 13 & $50,00 \%$ \\
\hline 4 & $1,04-3,67$ & Rendah & 5 & $19,23 \%$ \\
\hline 5 & $<1,03$ & Sangat Rendah & 1 & $3,85 \%$ \\
\hline \multicolumn{3}{|c|}{ Jumlah } & 26 & $100,00 \%$ \\
\hline
\end{tabular}

b. Faktor Risiko FAT

Berdasarkan faktor risiko FAT, diperoleh nilai maksimum $=12$; nilai minimum $=$ 3 ; rerata $=7,85 ;$ standar deviasi $=2,68 ;$ median $=8$ dan modus $=9$. Selanjutnya, data dikategorikan menjadi lima kategori, yaitu kategori sangat rendah, rendah, sedang, tinggi, dan sangat tinggi berdasarkan nilai mean dan standar deviasi. Tabel 5 berikut merupakan distribusi frekuensi identifikasi FAT yang dialami atlet angkat besi putri dan atlet angkat berat putri DIY berdasarkan faktor risiko FAT.

Tabel 5. Distribusi Frekuensi Identifikasi FAT yang Dialami atlet angkat besi putri dan atlet angkat berat putri DIY berdasarkan Faktor Resiko

FAT

\begin{tabular}{|c|c|c|c|r|}
\hline \hline No & Kelas Interval & Kategori & Frekuensi & Persentase \\
\hline 1 & $\geq 11,86$ & Sangat tinggi & 4 & $15,38 \%$ \\
\hline 2 & $9,18-11,85$ & Tinggi & 5 & $19,23 \%$ \\
\hline 3 & $6,5-9,17$ & Sedang & 12 & $46,15 \%$ \\
\hline 4 & $3,82-6,49$ & Rendah & 2 & $7,69 \%$ \\
\hline 5 & $<3,81$ & Sangat Rendah & 3 & $11,54 \%$ \\
\hline \multicolumn{2}{|c|}{ Jumlah } & 26 & $100,00 \%$ \\
\hline
\end{tabular}

Identifikasi Female Athlete Triad (FAT) pada Atlet Persatuan Angkat Besi, Berat, dan Binaraga Seluruh Indonesia (PABBSI) DIY (Kukuh Wahyudin Pratama dan Cerika Rismayanthi) 


\section{PEMBAHASAN}

Hasil tersebut di atas menunjukkan bahwa atlet angkat besi putri dan atlet angkat berat putri DIY sangat rentan masuk dalam risiko FAT. Hal ini ditunjukkan pada hasil angket bahwa terdapat atlet berdasarkan kecenderungan FAT dan faktor risiko FAT yang masuk dalam kategori tinggi. Selain kondisi yang menunjukkan terdapat atlet yang masuk dalam kategori tinggi juga ditunjukkan oleh terdapatnya atlet yang mengalami gangguan menstruasi, pola makan yang tidak teratur dengan konsumsi yang kurang dari jumlah kalori yang dibutuhkan, dan tidak sedikit dari atlet angkat besi putri dan atlet angkat berat putri DIY mengalami osteoporosis yang masuk dalam kategori sedang.

Selain penyebab yang telah disebutkan kemungkinan terdapat hal-hal yang lain yang menyebabkan terjadinya FAT pada atlet angkat besi putri dan atlet angkat berat putri DIY yang di antaranya adalah:

1. Intensitas latihan fisik yang terlalu tinggi yang tidak mampu dikompensasi oleh fisiologis tubuh.

2. Tekanan mental yang berat akibat kompetisi olahraga yang mencetuskan gangguan perilaku makan.

3. Tekanan untuk menang dalam suatu kompetisi "dengan cara apa pun".

4. Tuntutan untuk menang yang sangat ketat dari pelatih dan orangtua.

5. Isolasi sosial yang diakibatkan oleh latihan yang sangat intensif.

6. Kecenderungan fisiologis untuk mudah mengalami kenaikan berat badan.

Dari hasil tersebut perlu adanya penanggulangan supaya atlet angkat besi putri dan atlet angkat berat putri DIY dapat mengurangi risiko FAT. Menurut Golden (202: 37), bahwa untuk pecegahan FAT dapat dilakukan melalui jalur pendidikan. Apabila atlet diberikan pengetahuan yang baik tentang FAT, sangat memungkinkan terjadinya resiko FAT dapat terkurangi. Meskipun demikian, pada saat latihan bisa dilakukan dengan cara pendekatan terhadap atlet dengan diberikan pengetahuan akan risiko FAT. Oleh sebab itu perlunya pengetahuan yang lebih pada atlet terutama tentang risiko FAT agar supaya dapat mengurangi risiko terjadinya FAT pada setiap atlet terutama atlet angkat besi putri dan atlet angkat berat putri DIY. 


\section{DAFTAR PUSTAKA}

Benson, J.E., Engelbert, K.A., Eisenman, P,A,,(1996), Nutritional Aspect of FemaleAtlete Triad (FAT) in the Female Atlete Triad (FAT), International Jurnal of Sports Nutrition, 6:2.

Carbon, R.J. (1992). The Female Athlete. Dalam Textbook of Science and Medicine in Sport, Bloomfield, Fitch, Blackwell Scientific Publications.

Diah Emilia. (2012). Metode Latihan Atlet PABBSI Putri. Diakses dari: http://cbcmwbpfoffiicial.blogspot.com/2013/06/pabbsi-indonesian-officials-were.htmlpada tanggal 3 Desember 2013 pukul 19.28 WIB.

Golden, N.H., (2002). A Review of the Female Atlete Triad (FAT). International Journal Adolescent Medicine, 14:1.

Hans Tandra. (2011). Segala Sesuatu yang Harus Anda Ketahui tentang Osteoporosis. Surabaya: Gramedia.

Herbrich L, Pfeiffer E, Lehmkuhl U, dan Schneider N. (2011). Anorexia Athletica in Preprofessional Ballet Dancers. Diakses dari: http://www.ncbi.nlm.nih.gov/ pmc/articles/PMC3289170/ pada tanggal 28 januari 2014 pukul 11.33 WIB.

Kaziz, K., Iglesias, E. (2003). The Female Atlete Triad (FAT). AdolesenceMedicine,14:1.

Komar Hidayat. (2007). Wanita dalam Olahraga. Bandung: UPI.

Lippincott Williams \& Wilkins. (2006). Sport Medicine. New York: American College of Sport Medicine. Diakses dari: http://books.google.co.id/books/about/ACSM_s_ Guidelines_for_Exercise_Testing_a.html?hl=id\&id=8cRfd7GFZjMC. Pada tamggal 2 Februari 2014 pukul 09.40 WIB.

Militarry Women. (2009). Medicine and Science in Sports and Exercise. Clinical Sports Medicine, 30:5.

Nattiv, A., Agostini R. Yeager. K., (1994), The.Female Atlete Triad (FAT): The Inter Relatednessof Disorder Eating, Female Atlete Triad (FAT) andOsteoporosis. Clinical Sports Medicine,13:2.

Torstveit, M.T., Sundgot-Borgen, J., (2005). The Female Thlete Triad: Are Elite Athletes at Increased Risk? Medicine and Science in Sports andExercise, 37:2.

Identifikasi Female Athlete Triad (FAT) pada Atlet Persatuan Angkat Besi, Berat, dan Binaraga Seluruh Indonesia (PABBSI) DIY (Kukuh Wahyudin Pratama dan Cerika Rismayanthi) 